\title{
O PRINCÍPIO DA IGUALDADE DE TRATAMENTO NO DIREITO PRIVADO ALEMÃO*
}

\author{
JÖRG NEUNER ${ }^{* *}$
}

RESUMO: O princípio da igualdade de tratamento - assim como o princípio da autonomia privada - está enraizado na garantia da dignidade da pessoa humana, prevista na norma basilar do art. $1^{\circ}$ da Lei Fundamental alemã. O objetivo da presente contribuição consiste em, por um lado, trabalhar a legitimação e a estrutura dos deveres de igualdade de tratamento no direito privado e, por outro lado, apresentar o direito de auto-determinação e as opções de configuração dos atores de direito privado. Para isto serão primeiramente esboçados, separadamente, ambos os princípios da autonomia privada e da igualdade de tratamento, a fim de se poder, na sequência, descrever do ponto de vista dogmático a posição concreta do enunciado da igualdade no direito privado alemão.

PALAVRAS-CHAVE: Autonomia Privada - Igualdade de Tratamento - Proteção contra Discriminação - Dignidade da Pessoa Humana.

ABSTRACT: The principle of equal treatment - as well as that of contractual freedom is rooted in the guarantee of human dignity as laid down in the fundamental state norm of Article 1 of the Basic Law for the Federal Republic of Germany. The following essay aims on one hand to define the legitimation and the structure of equal treatment requirements in private law and on the other hand to point out the right of self-determination and the possibilities of action for private law actors. To this end the two principles of contractual freedom and equal treatment are first outlined separately in order to subsequently describe dogmatically the precise position of the principle of equality in German private law.

KEY-WORDS: Contractual Freedom - Equal Treatment - Protection Against Discrimination - Human Dignity.

SUMÁRIO: I. Introdução. II. O princípio da dignidade humana. III. O princípio da autonomia privada. IV. O princípio da igualdade de tratamento. V. O sistema de direito privado.

\section{INTRODUÇÃO}

Na Alemanha foi recentemente publicado um artigo sobre proteção contra discriminação no direito contratual brasileiro. ${ }^{1}$ Nele é demonstrado que a Constituição

\footnotetext{
* O presente artigo é a versão ampliada e acrescida de notas de rodapé de palestra proferida pelo Autor em setembro/outubro de 2007 nas cidades de Porto Alegre (VI Seminário Internacional de Direitos Fundamentais: Constituição, Direitos Fundamentais e Direito Privado - Pontifícia Universidade Católica do Rio Grande do Sul - 27.9), Brasília (Seminário Diálogos Constitucionais - Instituto Brasiliense de Direito Público - 1.10) e Rio de Janeiro (Ciclo de palestras sobre Direito Civil-Constitucional - Centro de Estudos da ProcuradoriaGeral do Município do Rio de Janeiro - 03.10). Traduzido por Pedro Scherer de Mello Aleixo

*** Catedrático de Direito Civil, Direito do Trabalho, Direito Comercial e Filosofia do Direito na Universidade de Augsburg - Alemanha.

${ }^{1}$ Cf. CESA FERREIRA DA SILVA, Der Diskriminierungsschutz im brasilianischen Vertragsrecht.
} 
brasileira é uma Constituição "dirigente”, cujos direitos fundamentais desenvolvem, ao menos, uma eficácia direta "prima facie", e implicam, com isso, também uma correspondente proteção contra discriminação no direito privado. Respaldando isto, especialmente 0 art. $3^{\circ}$ da Constituição brasileira contém um fundamento abrangente de legitimação para medidas legislativas e judiciais de proteção contra discriminação. No plano da legislação ordinária, a proteção contra discriminação é garantida por meio das possibilidades de ajuizar uma ação de prestar um fato negativo, da decretação de nulidade de negócios jurídicos, do direito à rescisão, bem como de pretensões imateriais de indenização. Uma proteção adicional é realizada pelo Código de Defesa do Consumidor brasileiro (CDC), segundo o qual a vinculatividade de uma oferta contratual ocorre, com frequência, já no momento da preparação das negociações contratuais, e não representa uma mera "invitatio ad offerendum" não vinculativa para o empresário.

Diferentemente da ordem jurídica brasileira, na Alemanha existiu por muito tempo apenas uma proteção muito restrita contra discriminação. A situação jurídica modifica-se primeiramente, de modo fundamental, a partir do ano 2000, por meio da promulgação de quatro diretivas antidiscriminatórias pela União Européia, as quais precisavam ser implementadas pelos Estados-Membros no seu direito nacional. ${ }^{3}$ Enquanto duas diretivas dizem respeito especialmente ao direito do trabalho, as outras duas valem para todo o direito privado, nomeadamente a diretiva 2000/43/EG ${ }^{4}$, sobre a aplicação do princípio da igualdade de tratamento entre as pessoas, sem distinção de origem racial ou étnica, bem como a diretiva 2004/113/EG 5 , sobre a realização do princípio da igualdade de tratamento entre homens e mulheres no acesso a bens e

In: NEUNER (Org.), Grundrechte und Privatrecht aus rechtsvergleichender Sicht, 2007, p. 289 ss.; ver, além disso, ainda, do mesmo autor, A Proteção contra Discriminação no Direito Contratual Brasileiro. In: PINTO MONTEIRO, NEUNER, SARLET (Orgs.), Direitos Fundamentais e Direito Privado - Uma Perspectiva de Direito Comparado, 2007, p. 389 ss.; foi, ademais, também publicado na Alemanha e em Portugal um estudo de direito comparado a respeito da proteção contra discriminação, cf. KERN, Rassendiskriminierung im Zivilrecht, 2007.

${ }^{2}$ Cf. SARLET, Soziale Grundrechte und Privatrecht behandelt am Beispiel Brasiliens. In: Festschrift CANARIS, vol. II, 2007, p. 771 ss. (787 ss.); do mesmo autor, A Influéncia dos Direitos Fundamentais no Direito Privado: O Caso Brasileiro. In: PINTO MONTEIRO, NEUNER, SARLET (Orgs.), Direitos Fundamentais e Direito Privado - Uma Perspectiva de Direito Comparado, 2007, p. 111 ss. (124 ss.), com documentação comprobatória adicional.

${ }^{3}$ Ver, pormenorizadamente, STORK, Das Anti-Diskriminierungsrecht der Europäischen Union und seine Umsetzung in das deutsche Zivilrecht, 2006, p. 101 ss., com documentação comprobatória adicional; ver, além disso, com respeito à implementação em outros Estados europeus, também o panorama apresentado em http://ec.europa.eu/employment_social/fundamental_rights/legis/lgms_de.htm, bem como THÜSING. In: Münchener Kommentar, 5. ed. 2007, introdução à Lei Geral de Igualdade de Tratamento, números de margem 25 ss., com documentação comprobatória adicional; com respeito à moldura de direito internacional relativa à legislação anti-discriminação, ver RUDOLF. In: RUDOLF/MAHLMANN, Gleichbehandlungsrecht, 2007, § 2 (p. 58 ss.), com documentação comprobatória adicional.

${ }^{4}$ OJEC L 180/22 (19 de julho de 2000) - publicada, em Portugal, no Jornal Oficial $n^{\circ}$ L 180/22, de 19 de julho de 2000; ver, em pormenor, a respeito da origem histórica, BROWN, The Race Directive: Towards Equality for All the Peoples of Europe? (2001-2002) 21 Yearbook of European Law 197 ss.; NIESSEN/CHOPIN, The Starting Line and the Racial Equality Directive. In: NIESSEN/CHOPIN, The Development of Legal Instruments to Combat Racism in a Diverse Europe (2004): 95 ss.

${ }^{5}$ OJEC L 373/37 (21 de dezembro de 2004) - publicada, em Portugal, no Jornal Oficial no L 373/37, de 21 de dezembro de 2004. 
serviços e seu fornecimento. Na Alemanha, estas diretivas antidiscriminatórias não foram apenas implementadas uma a uma, tendo sido, para além disso, promulgada uma Lei Geral de Igualdade de Tratamento, que prevê uma abrangente proteção de direito privado contra discriminação, a qual também compreende desfavorecimentos por motivo de religião, deficiência, idade e identidade sexual. ${ }^{6}$

Estas iniciativas legislativas encontraram, na Alemanha, massivas objeções científicas e político-jurídicas. Muitos autores falam até mesmo da "morte da autonomia privada”, a qual seria iminente por conta de tais medidas antidiscriminatórias. ${ }^{7}$ A autonomia privada não é, todavia, ameaçada apenas por uma intervenção excessiva em direitos de liberdade, mas também por uma insuficiente consideração das condições materiais da liberdade, às quais também pertence, de modo essencial, a proteção diante da discriminação. Acresce a isto o fato de a atual legislação antidiscriminatória constituir apenas um sub-caso do princípio geral da igualdade de tratamento no direito privado. Gostaria, por este motivo, de olhar mais além e de discutir, de modo bastante geral, o enunciado da igualdade no direito privado alemão.

\section{O PRINCÍPIO DA DIGNIDADE HUMANA}

Levando em consideração sua ênfase, o mandado de igualdade de tratamento é - evidentemente - um domínio do direito público. Diferentemente disto, podem os cidadãos, em princípio, definir entre si livremente os seus relacionamentos jurídicos e mesmo determinar com quem e sob quais condições querem contrair obrigações jurídico-negociais. Esta distinção categorial entre Estado e sociedade não vale, no entanto, de modo absoluto, uma vez que ambos os sistemas se assentam sobre um fundamento comum de máximas jurídicas fundamentais, as quais servem, na mesma medida, à proteção do indivíduo. Pode-se visualizar esta interdependência entre direito público e privado por meio de diversos exemplos: assim, não existe uma pretensão constitucionalmente assegurada de garantia do mínimo existencial apenas diante do Estado, mas também obrigações de contratar entre atores de direito privado para o fornecimento de bens necessários à vida ${ }^{8}$, pretensões de pensões alimentícias por parte de familiares necessitados ${ }^{9}$ e, ainda de modo exemplificativo, a proibição da penhora total no processo de execução ${ }^{10}$. De modo análogo à proteção de interesses materiais fundamentais, há em ambos os âmbitos jurídicos também direitos prestacionais de natureza informativa, os quais realizam, por sua vez, efeitos distributivos no

\footnotetext{
${ }^{6}$ Ver, pormenorizadamente, com respeito às regulamentações gerais de direito civil relativas à Lei Geral de Igualdade de Tratamento, ARMBRÜSTER. In: RUDOLF/MAHLMANN, Gleichbehandlungsrecht, 2007, $\S 7$ (p. 257 ss.), com documentação comprobatória adicional.

7 Cf., apenas, SÄCKER, „Vernunft statt Freiheit!“ - Die Tugendrepublik der neuen Jakobiner Referentenentwurf eines privatrechtlichen Diskriminierungsgesetzes, ZRP 2002, 286 (289); de modo semelhante, ADOMEIT, Diskriminierung - Inflation eines Begriffs, NJW 2002, 1622 (1623).

${ }^{8}$ Ver, em pormenor, LARENZ/WOLF, Allgemeiner Teil des Bürgerlichen Rechts, 9. ed. 2004, § 34, números de margem 31 ss., com documentação comprobatória adicional.

${ }^{9}$ Cf. $\S \S 1601$ e 1602 I BGB [§ 1601 - Obrigados a prestar alimentos: Parentes em linha direta são obrigados a garantir pensão alimentícia uns aos outros. § 1602 - Necessidade: (1) Só é credor alimentar quem não estiver em condições de sustentar a si próprio].

${ }^{10}$ Cf., nomeadamente, nas penhoras de coisas, o $\$ 811$ do Código de Processo Civil (ZPO), bem como, nas penhoras de salário, os §§ 850a ss. da ZPO.
} 
direito privado. É de se pensar na pretensão de informação do filho de indicação do nome do pai contra a mãe ${ }^{11}$, mas também em deveres de fornecimento de informações pré-contratuais, que devem otimizar o processo de decisão dos potenciais parceiros contratuais, tais como o dever pré-contratual de um empresário esclarecer o consumidor sobre direitos especiais de retratação, isto é, o dever de um parceiro contratual informar o outro sobre as possibilidades de resolução do contrato. Como último exemplo de uma máxima fundamental comum deve ser, finalmente, acentuado o aspecto da ausência de esperança e de perspectiva. ${ }^{12}$ Assim, o Tribunal Constitucional Federal considerou, com respeito às penas perpétuas privativas de liberdade, afetado o núcleo da dignidade humana "quando o condenado, a despeito do desenvolvimento de sua personalidade, precisa abandonar toda esperança de recuperar sua liberdade". ${ }^{13}$ O mesmo pensamento fundamental se expressa também em diferentes pontos do direito civil alemão. Assim, são nulos os negócios obrigacionais acerca do patrimônio futuro - conforme o $\S 311, b$, alínea 2, do Código Civil (BGB) -, são ineficazes as vinculações contratuais eternas - conforme o $\S 138$ do BGB - e o processo de insolvência do consumidor deve igualmente retirar o devedor do endividamento, em princípio temporalmente ilimitado. A este contexto pertence também uma temática bastante atual, relativa ao âmbito da assim chamada "disposição dos pacientes sobre a própria vida”. Contra a - recentemente manifestada - concepção do Conselho Nacional de Ética ${ }^{14}$, afigura-se, na minha opinião, juridicamente ineficaz também a exclusão - declarada com base na autonomia privada - da possibilidade de revogação de uma "disposição dos pacientes sobre a própria vida". Uma tal auto-vinculação, que declara não ser considerável uma futura exigência por medidas conservadoras da vida (por exemplo, a exigência concludente de alimentação artificial mediante tubo alimentar no estágio avançado de uma doença demencial), não é compatível nem com os parâmetros do direito civil, nem do direito constitucional.

O fundamento jurídico-constitucional para estas restrições à autonomia privada constitui a proteção da dignidade humana, conforme o art. $1^{\circ}$ da Lei Fundamental, combinado com o princípio do Estado social. Pode-se ver a força de atuação abrangente do art. $1^{\circ}$ da Lei Fundamental no direito privado de modo muito expressivo nos Protocolos Constituintes, onde se refere expressamente: "o art. $1^{\circ}$ deve também obrigar às pessoas privadas”. ${ }^{15}$ Mediante inversão do argumento subjacente a esta regulamentação excepcional, os demais direitos fundamentais, especialmente os enunciados de igualdade do art. $3^{\circ}$ da Lei Fundamental, não desenvolvem no entanto - uma eficácia horizontal ${ }^{16}$, mas apenas, em uma forma enfraquecida,

${ }^{11}$ Cf. Coletânea Oficial das Decisões do Tribunal Constitucional Federal (BVerfGE) 96, 56 ss. (61 ss.); 90, 263 ss. (271); PALANDT/DIEDERICHSEN, Bürgerliches Gesetzbuch, 66. ed. 2007, introdução ao § 1591, número de margem 3, com documentação comprobatória adicional.

${ }^{12}$ Ver a respeito, ainda, NEUNER, In: SARLET, Constituição, Direitos Fundamentais e Direito Privado, 2. ed. 2006, p. 247 ss. (257 s.).

${ }^{13}$ BVerfGE 45, 187 ss. (245); 64, 261 ss. (272).

${ }^{14}$ Cf. NATIONALER ETHIKRAT, Patientenverfügung, 2005, p. 34

${ }^{15}$ Bericht über den Verfassungskonvent auf Herrenchiemsee vom 10. bis 23. August 1948, p. 21.

${ }^{16}$ É diverso, no entanto, o ponto de partida (especialmente do ponto de vista normativo-textual) jurídicoconstitucional existente no Brasil; cf., em pormenor, SARLET, A Influéncia dos Direitos Fundamentais no 
implicam deveres de proteção. ${ }^{17}$ A norma fundamental do art. $1^{\circ}$ da Lei Fundamental também não deve ser - em uma consequência adicional - degradada à condição de “moeda pequena” no direito civil, sobretudo pelo fato de a autonomia privada pertencer ao núcleo da dignidade humana. Quero, por isso, tentar trabalhar, na sequência, a legitimação e a estrutura dos deveres de igualdade de tratamento no direito privado, e, ao mesmo tempo, porém, apresentar os limites da obrigação social dos particulares e demonstrar a relativa autonomia do direito privado. Para tanto, primeiro esboçarei, separadamente, ambos os princípios opostos da autonomia privada e da igualdade de tratamento, a fim de, na sequência, descrever concretamente a posição do enunciado da igualdade no sistema de direito privado.

\section{O PRINCÍPIO DA AUTONOMIA PRIVADA}

Buscando-se, de início, determinar mais de perto o conceito de autonomia privada, faz-se necessária uma confrontação principiológica com a idéia de liberdade. Trata-se aqui de um problema jurídico geral, discutido de maneira análoga no plano dos direitos fundamentais, onde diferenciam-se essencialmente duas concepções básicas $^{18}$ : por um lado, a idéia de liberdade formal, que se caracteriza pelo fato de ser deixada ao próprio titular de direitos fundamentais a definição de liberdade e a decisão - tomada de modo autônomo, de acordo com as suas próprias preferências de dela fazer uso. Na perspectiva da sociedade, fala-se, por isso, também, de liberdade "negativa”, pois o Estado está precisamente impedido de determinar - sob o ponto de vista do conteúdo - o conceito de liberdade ${ }^{19}$. Desta compreensão liberal de direitos fundamentais há de se diferenciar, por outro lado, um conceito de liberdade materialmente forjado, que não leva em conta a liberdade pura e simplesmente, mas sempre e tão somente a liberdade "para o que", direcionada, portanto, à realização de determinados valores ou processos. De modo similar, pode-se também distinguir para o caso especial de direito civil relativo à autonomia privada - entre concepções materiais e formais. $^{20}$

\section{A Concepção Material}

De acordo com a tese material, a autonomia privada serve à realização de determinados fins e não se deixa limitar ao aspecto da autodeterminação individual. O direcionamento finalístico pode ser, com isso, definido de modo bastante diferente e alcançar desde noções gerais de justiça, passando por uma "garantia de correção", até interesses coletivos. Em retrospectiva histórica, a idéia de liberdade material encerra sobretudo o risco de uma absolutização de interesses comunitários. No nacional-

Direito Privado: O Caso Brasileiro. In: PINTO MONTEIRO, NEUNER, SARLET (Orgs.), Direitos Fundamentais e Direito Privado - Uma Perspectiva de Direito Comparado, 2007, p. 111 ss.

${ }^{17}$ Ver, em pormenor, NEUNER, A Influéncia dos Direitos Fundamentais no Direito Privado Alemão. In: PINTO MONTEIRO, NEUNER, SARLET (Orgs.), Direitos Fundamentais e Direito Privado - Uma Perspectiva de Direito Comparado, 2007, p. 213 ss. (227 ss.); do mesmo autor, O Código Civil da Alemanha (BGB) e a Lei Fundamental. In: SARLET, Constituição, Direitos Fundamentais e Direito Privado, 2. ed. 2006, p. 247 ss. (262 ss.).

${ }^{18}$ Ver, em pormenor, NEUNER, Privatrecht und Sozialstaat, 1998, p. 9 s., com documentação comprobatória adicional.

${ }^{19}$ Cf. HAVERKATE, Verfassungslehre, 1992, p. 158, nota de rodapé 2.

${ }^{20}$ Ver, em pormenor, SCHIEK, Differenzierte Gerechtigkeit, 2000, p. 290 ss., com documentação comprobatória adicional. 
socialismo, por exemplo, o contrato foi interpretado como "meio de configuração do ordenamento popular" e, como consequência ulterior, foi negada aos "camaradas de etnia" ("Volksgenossen") a capacidade de serem titulares de direitos fundamentais. ${ }^{21}$ De modo similar, na teoria do direito marxista o ator de direito privado não é respeitado como titular individual de liberdade, mas tão somente retratado como um membro de sua espécie ("Gattungswesen"), ${ }^{22}$ conduzido por "conhecimentos advindos de necessidades objetivas”. ${ }^{23}$

A despeito de tais riscos de absolutização, um conceito material de liberdade não faz - de modo bastante geral - suficentemente jus ao papel dos atores de direito privado como cidadãos responsáveis. Já é questionável o ponto de partida teórico, no sentido de uma compreensão finalística de liberdade, uma vez que a autonomia privada não serve à realização de uma ordem de preferência estabelecida de modo heterônomo, mas, pelo contrário, volta-se à realização de concepções subjetivas. ${ }^{24}$ Esta avaliação corresponde, além disso, também à lex lata, que, apenas em constelações excepcionais - por exemplo, no caso de violação aos bons costumes -, intervém no mecanismo contratual e não prevê um controle geral de conteúdo.

\section{A Concepção Formal}

Como ponto de partida, é de se preferir, assim, um modelo formal de liberdade, que concede aos sujeitos individuais de direito privado a competência para atuação jurídico-negocial autodeterminada, sem depender de aspectos materiais de justiça ou de outros critérios de correção. ${ }^{25}$ Nas palavras de Immanuel Kant: “ninguém pode forçar-me a ser feliz do seu modo, senão que cada um deve procurar sua felicidade pelo caminho que a ele próprio aprouver". ${ }^{26}$

Uma tal compreensão puramente formal de liberdade está, todavia, também exposta a objeções, por atuar, tendencialmente, às expensas da autodeterminação coletiva, bem como de interesses legítimos de terceiros. ${ }^{27}$ Ela perde de vista situações de desequilíbrio social, cria hierarquias econômicas e impele o Estado para um mero papel de guarda-noturno. Estes riscos são, todavia, combatidos quando se compreende a proteção da liberdade formal de contratar pura e simplesmente como um "mandado de otimização"28 que deve ser harmonizado com princípios contrapostos. Por meio de

\footnotetext{
${ }^{21}$ Ver, em pormenor, FRASSEK, Von der „völkischen Lebensordnung“ zum Recht. Die Umsetzung weltanschaulicher Programmatik in den schuldrechtlichen Schriften von Karl Larenz (1903 - 1993), 1996, p. 85 ss.; LA TORRE, Der Kampf wider das subjektive Recht, Rechtstheorie 23 (1992), 355 ss., com documentação comprobatória adicional.

${ }^{22}$ MARX, Zur Judenfrage. In: MARX/ENGELS, Werke, vol. I, 1961, p. 347 ss. (364).

${ }^{23}$ KLENNER, Die marxistische Menschenrechts-Konvention. In: GS Marcic, 1974, p. 793 ss. (801).

${ }^{24}$ Cf., ainda, CANARIS, Wandlungen des Schuldvertragsrechts - Tendenzen zu seiner „Materialisierung“, AcP 200 (2000), p. 273 ss. (277 ss.); SINGER, Selbstbestimmung und Verkehrsschutz im Recht der Willenserklärungen (1995), 39 ss.

${ }^{25}$ Cf. LORENZ, Der Schutz vor dem unerwünschten Vertrag, 1997, p. 15 ss.; FASTRICH, Richterliche Inhaltskontrolle im Privatrecht, 1992, p. 36 ss.

${ }^{26}$ Über den Gemeinspruch: Das mag in der Theorie richtig sein, taugt aber nicht für die Praxis; Ausgabe der Preußischen Akademie der Wissenschaften, vol. VIII, 1912, p. 273 ss. (290).

${ }^{27}$ Ver, em pormenor, NEUNER, Privatrecht und Sozialstaat, 1998, p. 85 ss.

${ }^{28}$ Cf. ALEXY, Theorie der Grundrechte, 1986, p. 75 ss., com documentação comprobatória adicional.
} 
uma tal relativização, a autonomia privada permanece, por um lado, reconhecida como um valor independente e, por outro, são levados em conta interesses legítimos de terceiros. De maneira significativa, este sistema dual verifica-se também no plano dos direitos humanos, no qual há, ao lado dos clássicos direitos de liberdade, uma segunda geração de direitos sociais, passível de ser ponderada com os primeiros. Devem ser exemplificativamente destacadas apenas ambas as Convenções sobre “direitos civis e políticos”, de um lado, e "direitos econômicos, sociais e culturais", de outro. $^{29}$ A concepção de direitos humanos também não conduz, com isso, a uma interpretação material da autonomia privada, sendo os interesses em disputa explicitados e, através disso, alcançada uma elevada medida de transparência e de clareza metodológica.

\section{O PRINCÍPIO DA IGUALDADE DE TRATAMENTO}

Dentre os princípios contrapostos à autonomia privada inclui-se, especialmente, o princípio da igualdade de tratamento. Dessa relativização não decorre, todavia, uma restrição global da autonomia privada. O princípio da igualdade de tratamento constitui, antes, um direito social em rota de colisão, que apresenta estruturas específicas e exige uma intervenção nos direitos de liberdade apenas em casos excepcionais. ${ }^{30}$

\section{A Natureza Jurídica de Direito Social de Participação}

Que o enunciado da igualdade apresenta, no direito privado, uma natureza social e participativa, torna-se imediatamente claro quando se visualizam casos clássicos de discriminação, como aquele no qual o empregador não quer contratar mulheres, ou o hoteleiro não quer atender estrangeiros.

Evidentemente, é também possível nestas constelações, de modo cumulativo, uma violação do direito de personalidade do discriminado - caso, por exemplo, o hoteleiro pendure uma placa com dizeres xenófobos em frente à porta do seu restaurante ou o empregador opte por uma formulação ofensiva em sua carta de recusa. Contra isto, tanto o direito civil delitual como o direito penal asseguram uma correspondente proteção jurídico-defensiva à integridade. ${ }^{31}$

Em contraste, pode-se imaginar, todavia, também o frequente caso em que não há nenhum abuso discriminatório, mas alguém pura e simplesmente não quer contrair

\footnotetext{
${ }^{29}$ Ver, além disso, ainda, a "Convenção para Proteção dos Direitos Humanos e Liberdades Fundamentais” (BGBl. 1952 II, p. 685 ss.), bem como a "Carta Social Européia” (BGBl. 1964 II, p. 1261 ss.); cf., ainda, na literatura, nomeadamente, ZACHER, Sozialpolitik und Menschenrechte in der Bundesrepublik Deutschland, 1968, p. 29; TUGENDHAT, Die Kontroverse um die Menschenrechte. In: GOSEPATH/ LOHMANN, Philosophie der Menschenrechte, 1998, p. 48 ss. (55 ss.).

${ }^{30}$ Um problema especial constitui a validade das razões para a igualdade de tratamento em se tratando de deliberações majoritárias em associações, pois não se trata, aqui, de contratos; ver, em pormenor, a respeito desta temática, VERSE, Der Gleichbehandlungsgrundsatz im Recht der Kapitalgesellschaften, 2006, p. 3 ss.; HUECK, Der Grundsatz der gleichmäßigen Behandlung im Privatrecht, 1958, p. 35 ss., 333 ss.; RAISER, Der Gleichheitsgrundsatz im Privatrecht, ZHR 111 (1948), 75 ss. (81 ss.), com documentação comprobatória adicional.

${ }^{31}$ Ver, ainda, com respeito às duas dimensões da proteção contra discriminação no direito privado em conformidade à iustitia commutativa e à iustitia distributiva, MOTA PINTO, Autonomia privada e discriminação - algumas notas. In: Estudos em Homenagem ao Conselheiro José Manuel Cardoso da Costa, vol. II (2005), p. 313 ss. (328 ss., 332 ss.).
} 
relações contratuais com determinados grupos populacionais e, por isso, a cada vez, recusa - de maneira amistosa, mas consequente - uma celebração de contrato. Se um empregador não quiser contratar mulheres ou um hoteleiro não quiser atender determinados grupos, esta mera omissão constitui, como tal, em seu núcleo, expressão da liberdade negativa de contratar. Os motivos por detrás disto existentes podem ser manifestamente iníquos ou moralmente rejeitáveis, mas são, em princípio, juridicamente irrelevantes. Nós não temos nem um direito penal voltado aos sentimentos (Gesinnungsstrafrecht), nem um direito civil delitual voltado aos sentimentos (Gesinnungsdeliktsrecht), que proíbam atitudes hostis às mulheres ou aos estrangeiros. As regulamentações antidiscriminatórias de direito privado também não se deixam, nessa medida, legitimar como sanção a uma atuação não permitida, no sentido dos $\S \S 823$ ss. do BGB, uma vez que a nova Lei de Igualdade de Tratamento constitui, em grande parte, uma socialização do direito privado. O mandado de tratamento igualitário é uma reivindicação social no sentido da iustitia distributiva, que se define como justiça em consideração à pessoa. ${ }^{32}$ Logo, a questão decisiva é se os sujeitos de direito privado podem ser compelidos a contrair relações jurídico-negociais com determinados grupos de pessoas e a conformá-las de acordo com o enunciado da igualdade.

\section{A Legitimação da Reivindicação Social}

Uma igualdade de tratamento no direito privado pode ser, essencialmente, justificada e devida por três motivos: para proteção do indivíduo, para proteção do grupo envolvido e no interesse da coletividade. ${ }^{33}$

\section{a) A proteção do indivíduo}

A necessidade de uma proteção individualizada contra a discriminação dos indivíduos já se mostra pelo fato de a liberdade jurídica correr o risco de cair no vazio se faltarem os pressupostos fáticos para a sua observância. ${ }^{34}$ Fossem cidadãos sistematicamente excluídos da sociedade e privados dos seus bens em virtude de uma determinada característica, lhes seria, em última consequência, recusado até mesmo o necessário mínimo existencial. ${ }^{35}$ A proteção contra a discriminação serve, por conseguinte, à consideração da dignidade humana, ao limitar a liberdade de um ator de direito privado em favor das possibilidades de desenvolvimento de outro.

\section{b) A proteção do grupo}

Regulamentações antidiscriminatórias podem, além disso, servir à proteção de um grupo. ${ }^{36}$ Assim, por exemplo, são os deficientes tendencialmente desfavorecidos

${ }^{32}$ Cf., apenas, CANARIS, Die Bedeutung der iustitia distributiva im deutschen Vertragsrecht, 1997, p. 11 s.

${ }^{33}$ Cf., ainda, MOTA PINTO, Autonomia privada e discriminação - algumas notas. In: Estudos em Homenagem ao Conselheiro José Manuel Cardoso da Costa, vol. II (2005), p. 313 ss. (326 ss.).

${ }^{34}$ Cf., apenas, ALEXY, Theorie der Grundrechte, 1986, p. 458 ss.; MAHLMANN, Gerechtigkeitsfragen im Gemeinschaftsrecht. In: RUST (entre outros), Die Gleichbehandlungsrichtlinien der EU und ihre Umsetzung in Deutschland, 2003, p. 47 ss. (59); do mesmo autor, In: RUDOLF/MAHLMANN, Gleichbehandlungsrecht, 2007, § 1, número de margem 57 (p. 55 s.).

${ }^{35}$ Ver, com respeito ao exemplo da exclusão de terceiros da única fonte disponível de água potável, apenas, DIAS, Die sozialen Grundrechte: Eine philosophische Untersuchung der Frage nach den Menschenrechten, 1993, p. 89, com documentação comprobatória adicional.

${ }^{36}$ Ver, em pormenor, SCHIEK, Differenzierte Gerechtigkeit, 2000, p. 39 ss., com documentação comprobatória adicional. 
- em inúmeros âmbitos da vida - em virtude de suas particularidades constitutivas, como, por exemplo, no mercado de trabalho. Para equilibrar estes impactos estruturais negativos, podem ser devidas medidas protetivas (affirmative actions), ${ }^{37}$ como, por exemplo, obrigações de contratar ou tributos compensatórios. ${ }^{38}$

\section{c) A proteção da coletividade}

A proteção diante de discriminações pode ocorrer, finalmente, também no interesse de toda a sociedade. Uma sociedade que segrega determinadas parcelas da população põe em risco a sua paz interna, pois provoca a resistência dos desfavorecidos e correspondentes ações de solidariedade por parte de terceiros. ${ }^{39}$ Além disso, a forma democrática de Estado também não é desprovida de pressupostos; torna-se primeiramente efetiva, assim como a liberdade do indivíduo, quando existirem reais possibilidades de participação para todos os cidadãos. ${ }^{40}$ Por isso, pode ser, por exemplo, um objetivo legítimo intervir no mercado imobiliário para evitar a formação de guetos e, com isso, a instabilidade social que ameaça acontecer.

\section{A primazia do direito tributário}

De regra, tem o Estado, todavia, de realizar redistribuições por intermédio de seu sistema tributário. ${ }^{41}$ Por meio disto, os ônus sociais são distribuídos de modo justo, de acordo com a capacidade de prestação individual, e o enunciado da igualdade obtém outra vez validade em sua faceta direcionada ao Estado. Um tal procedimento encontra, contudo, limites fáticos, caso determinadas prestações somente puderem ser desempenhadas por particulares. É de se pensar, por exemplo, no fornecimento de bens necessários à vida ou na proteção do trabalhador em empresas privadas. Em tais constelações, a justiça distributiva exige uma obrigação social direta dos sujeitos de direito privado individuais, como que na condição de preço a ser pago pela renúncia de um abastecimento realizado nos moldes de uma economia planificada. ${ }^{42}$ Mesmo em tais obrigações sociais privadas vale, todavia, o princípio da proporcionalidade, de modo que tenha de ser estabelecido, no caso de encargos iníquos, um sistema estatal compensatório. $^{43}$

\footnotetext{
${ }^{37}$ V., com respeito aos problemas especiais envolvendo discriminação indireta e ações afirmativas, por exemplo, BARNARD/HEPPLE, Substantive Equality (2000) 59 Cambridge Law Journal 567 ss., 576 ss.; WADDINGTON/BELL, More Equal than Others: Distinguishing European Union Equality Directives (2001) 38 Common Market Law Review 592 ss., 601 ss.

${ }^{38}$ Ver, ainda, HEPPLE, Race and Law in Fortress Europe (2004) 67 The Modern Law Review 8 ss.; BELL/WADDINGTON, Reflecting on equalities in European equality law (2003) 28 European Law Review 353 ss.; MCCRUDDEN, International and European Norms Regarding National Legal Remedies for Racial Inequality. In: FREDMAN, Discrimination and Human Rights (2001): 255 ss.

${ }^{39}$ Ver, de há muito, VON STEIN, Geschichte der sozialen Bewegung in Frankreich von 1789 bis auf unsere Tage, (reimpressão de 1972), p. 36 ss.

${ }^{40}$ Ver, de modo basilar, HELLER, Politische Demokratie und soziale Homogenität, In: do mesmo autor, Gesammelte Schriften, vol. II, 1971, p. 421 ss. (427 ss.).

${ }^{41}$ Ver, ainda, ZACHER, Zur Rechtsdogmatik sozialer Umverteilung, DÖV 1970, 3 ss. (13 s.); EIDENMÜLLER, Effizienz als Rechtsprinzip, 1995, p. 273 ss.

${ }^{42}$ Cf. CANARIS, Die Bedeutung der iustitia distributiva im deutschen Vertragsrecht, 1997, p. 120; ver, especialmente em relação ao exemplo dos portadores de deficiência, NEUNER, Die Stellung Körperbehinderter im Privatrecht, NJW 2000, 1822 ss. (1823).

${ }^{43}$ Cf., ainda, BRITZ, Diskriminierungsschutz und Privatautonomie, VVdStRL 64 (2004), p. 355 ss. (379 ss.).
} 


\section{O princípio da subsidiariedade}

A caracterização do princípio da igualdade de tratamento como direito social de participação não serve apenas à explicação de intervenções na autonomia privada, mas também atua fundamentalmente na determinação da extensão dos deveres de proteção. ${ }^{44}$ Diferentemente dos direitos de defesa, os direitos de participação são limitados pelo princípio da subsidiariedade, segundo o qual todo cidadão é, em primeira linha, responsável por si próprio, devendo, se preciso for, levar terceiros em consideração segundo um critério de prioridade mais baixa. Assim, por exemplo, só é credor alimentar quem não tiver condições de sustentar a si próprio. Mesmo uma obrigação geral de contratar existe apenas no caso excepcional em que faltarem possibilidades razoáveis de evitação e forem necessários bens necessários à vida.

\section{O SISTEMA DE DIREITO PRIVADO}

Buscando-se, por fim, descrever em pormenor as restrições concretas de direito civil à autonomia privada por intermédio do enunciado da igualdade, há de se diferenciar várias modalidades de atuação. De modo correspondente à intensidade da intervenção na autonomia privada, pode-se distinguir três formas: mandados gerais de atuação, mandados limitados de igualdade de tratamento e meras proibições de diferenciação.

\section{Mandados Gerais de Atuação}

\section{a) Caracterização}

Analisando-se primeiramente o grupo de casos relativo aos mandados gerais de atuação, deixa-se ele caracterizar pelo fato de existirem deveres erga omnes e de o destinatário ter, em princípio, de contratar com qualquer pessoa. Tais deveres incondicionados de celebração contratual correspondem, nessa medida, ao princípio do tratamento igualitário, ao precisarem ser, em princípio, estabelecidos relacionamentos jurídico-negociais para todos os interessados.

\section{b) Legitimação}

Deveres gerais de atuação podem ser justificados mediante diferentes fundamentos. Eles podem, por um lado, servir à proteção de bens coletivos - como, por exemplo, à conservação de recursos. Assim, por exemplo, prevê o $\S 2^{\circ}$ da Lei de Fornecimento de Energia Elétrica o dever de obtenção de energia a partir de determinadas fontes energéticas renováveis. ${ }^{45}$ Por outro lado, deveres de celebração contratual garantem, no âmbito do necessário para prover a existência, o mínimo existencial - constitucionalmente protegido - de cada cidadão e se direcionam, em conformidade a isto, em primeira linha, a empresas privadas do ramo de abastecimento. ${ }^{46}$ Para além dos deveres de contratar prescritos pela legislação especial, resulta - de uma analogia total uma obrigação de celebração contratual para provedores de bens necessários à vida, na

${ }^{44}$ Ver, em pormenor, NEUNER, Privatrecht und Sozialstaat, 1998, p. 158 ss.

${ }^{45}$ Vinculado com uma regulamentação de remuneração mínima, conforme o $\S 3^{\circ}$ da Lei de Fornecimento de Energia Elétrica; ver, em pormenor, BUSCHE, Privatautonomie und Kontrahierungszwang, 1999, p. 493 s., 571, com documentação comprobatória adicional.

${ }^{46}$ Ver, apenas, LARENZ/WOLF, Allgemeiner Teil des Bürgerlichen Rechts, 9. ed. 2004, § 34, números de margem 31 s., com documentação comprobatória adicional. 
medida em que faltarem possibilidades razoáveis de evitação. ${ }^{47}$

Não obstante, fica o enunciado da igualdade - em se tratando deste grupo de casos - no pano de fundo, porquanto, a despeito de potenciais obrigações de terceiros, já existe uma pretensão originária de cada indivíduo, a qual pode também permanecer singular. O pensamento de igualdade torna-se primeiramente dominante diante da existência de recursos escassos, quando a demanda por um bem necessário à vida for maior do que a oferta. Neste caso, o provedor não deve privilegiar um dos necessitados segundo o seu próprio arbítrio; antes pelo contrário, devem ser aplicados, de regra, os princípios da iustitia distributiva. Assim, por exemplo, regulamenta o $\S 12$, alínea 3 , da Lei de Transplantes, que os órgãos humanos devem ser distribuídos de acordo com critérios objetivos concretos e não ao bel-prazer do doador.

\section{Mandados de Igualdade de Tratamento}

a) Caracterização

Diferentemente dos deveres gerais de atuação erga omnes, os mandados de igualdade de tratamento exigem apenas que pessoas de um determinado grupo sejam tratadas do mesmo modo. Tais deveres de igualdade de tratamento limitam o princípio da relatividade das relações jurídicas, ${ }^{48}$ quando uma determinada relação contratual repercute em relacionamentos jurídico-negociais de terceiros.

\section{b) Legitimação}

Os motivos justificadores dos deveres de igualdade de tratamento no direito privado são de diferente natureza. Eles podem, em primeiro lugar, resultar - como, por exemplo, na garantia de gratificações voluntárias no direito do trabalho ${ }^{49}-$ de uma relação especial de dependência. ${ }^{50}$ Eles podem, contudo, servir também à proteção de bens coletivos, por exemplo, de finalidades político-ordenatórias no direito dos cartéis. ${ }^{51}$ Além disso, pode ser justificado, do ponto de vista dos direitos fundamentais, que, a partir do art. $6^{\circ}$ da Lei Fundamental, os membros de uma família sejam tratados de modo igualitário. É de se pensar, por exemplo, no direito de entrada do cônjuge ou do parceiro na relação de aluguel, conforme o § 563 do BGB. Do mesmo modo, também o contrato com eficácia protetiva em favor de terceiros no sentido da fórmula "Wohl und Wehe" - implica um dever de igualdade de tratamento - próprio da estatalidade social - em relação aos membros de uma

\footnotetext{
${ }^{47}$ Ver, apenas, PALANDT/HEINRICHS, Bürgerliches Gesetzbuch, 66. ed. 2007, introdução ao § 145, números de margem 8 ss.; BYDLINSKI, Zu den dogmatischen Grundfragen des Kontrahierungszwanges, AcP 180 (1980), 1 ss. (41), com documentação comprobatória adicional.

${ }^{48}$ Ver, em pormenor, com respeito a este princípio, MEDICUS, Schuldrecht I, 16. ed., 2005, números de margem 30 ss.; NEUNER, Der Schutz und die Haftung Dritter nach vertraglichen Grundsätzen, JZ 1999, 126 ss. (126 s.).

${ }^{49}$ Ver, apenas, Tribunal Federal do Trabalho, NZA 2004, 803 ss. (807), com documentação comprobatória adicional.

${ }^{50}$ Ver, com respeito às diferentes abordagens de fundamentação, HUECK, Der Grundsatz der gleichmäßigen Behandlung im Privatrecht, 1958, p. 58 ss., 127 ss.; SCHLACHTER, Wege zur Gleichberechtigung, 1993, p. 88 ss., com documentação comprobatória adicional.

51 Ver, em pormenor, BUSCHE, Privatautonomie und Kontrahierungszwang, 1999, p. 301 ss., com documentação comprobatória adicional.
} 
família. ${ }^{52}$ Em contrapartida, no direito relativo ao aluguel de quartos residenciais, não vale, em princípio - de acordo com a opinião dominante e acertada -, a máxima da igualdade de tratamento, podendo o locador tratar de maneira desigual os locatários individuais como lhe convir. ${ }^{53}$

Um segundo caso especial de aplicação do princípio da igualdade de tratamento encontra-se no direito relativo às inexecuções obrigacionais. Se um devedor pretende - em virtude de possuir recursos limitados - uma liberação parcial da prestação, deve ele tratar de modo igualitário os vários credores, quando estes forem uns independentes dos outros. ${ }^{54}$ Um exemplo constitui o mandado de redução por quotas na extinção parcial não culposa de uma obrigação - limitada - de fornecer coisa infungível; quando, portanto, o vendedor aliena $60 \%$ de seu estoque ao credor $1 \mathrm{e}$ $40 \%$ ao credor 2 e, antes da entrega, é destruída - por caso fortuito - metade do seu inventário. O mesmo vale para a exceção de alimentos necessários, prevista no § 519 do BGB, na qual devem ser reduzidas, por cotas, as várias promessas simultâneas de doação. ${ }^{55}$ Em ambos os casos, o devedor assume o papel de um administrador da escassez diante de vários credores e pode apenas se desonerar de obrigações quando procede segundo princípios distributivos e não favorece um credor de maneira arbitrária.

\section{Proibições de Diferenciação}

\section{a) Caracterização}

Ao contrário dos mandados de igualdade de tratamento, as proibições de diferenciação não exigem um procedimento igualitário, mas reclamam pura e simplesmente que uma decisão - tomada com base na autonomia privada - não dependa de determinados critérios. ${ }^{56}$ Não é fundamentado, portanto, nenhum dever de tratar aquilo que é igual de modo igualitário, sendo apenas exluída uma opção especial de atuação. Assim, por exemplo, pode um empregador recusar uma candidata que concorre com homens, mas, conforme o $\S 7^{\circ}$ da Lei Geral de Igualdade de Tratamento, não em virtude do sexo. Mesmo as diretivas anti-discriminação da União Européia não constituem mandados de igualdade de tratamento em favor de um círculo de pessoas protegido, mas proíbem pura e simplesmente as respectivas diferenciações.

\section{b) Legitimação}

Tais proibições de diferenciação servem, em primeira linha, à proteção contra a exclusão social. Ninguém deve, por exemplo, ser desfavorecido em virtude de sua

\footnotetext{
${ }^{52}$ Cf., em pormenor, NEUNER, Diskriminierungsschutz durch Privatrecht, JZ 1999, 126 ss. (128 ss.), com documentação comprobatória adicional.

53 Ver, em pormenor, NEUNER, Privatrecht und Sozialstaat, 1998, p. 256, com documentação comprobatória adicional.

${ }^{54}$ Cf., em pormenor, NEUNER, Der Prioritätsgrundsatz im Privatrecht, AcP 203 (2003), 46 ss. (57 ss.).

55 Cf. § 519 BGB - Exceção dos alimentos necessários: (1) O doador está legitimado a recusar o cumprimento de uma promessa manifestada a título de doação, enquanto ele - considerando-se suas outras obrigações - estiver impossibilitado de cumprir a promessa sem que a sua adequada subsistência ou o cumprimento dos deveres de prestar alimentos que lhe acometem por força de lei estejam ameaçados. (2) Havendo pretensões de mais de um donatário, tem prioridade a pretensão antes originada.

${ }^{56}$ Ver, com respeito às proibições de diferenciação na perspectiva jurídico-constitucional, em pormenor, SACKSOFSKY, Das Grundrecht auf Gleichberechtigung, 2. ed., 1996, p. 23 ss.
} 
“origem étnica” ou sexo. Quanto mais “sinais” forem protegidos legislativamente, tanto mais forte, todavia, se realiza um nivelamento. Teoricamente, pode-se submeter todos os dados da personalidade a uma proibição de diferenciação, o que conduziria ao fim da autonomia privada e de uma ordem pluralista. Sobretudo as desigualdades econômicas e as discriminações a elas ligadas constituem manifestações imanentes ao sistema de uma ordem econômica alicerçada na liberdade. ${ }^{57}$ Pode-se identificar este fenômeno, na condição de arquétipo de um mercado liberal, já no Bazar Oriental, como Elias Canetti exemplificativamente descreveu em suas impressões de viagem, intituladas "As vozes de Marraquexe”: "Existem preços para pobres e preços para ricos, sendo os preços para os pobres naturalmente os mais elevados". ${ }^{58}$ Do mesmo modo, ocorre nos sistemas econômicos mais complexos: "The poor pay more". ${ }^{59}$ Tais discriminações realmente contradizem o pensamento de igualdade, mas representam o preço da renúncia a um abastecimento instituído nos moldes de uma economia planificada. É de se pensar, também, no fato de as discriminações não serem por si sós repudiáveis em um sistema alicerçado na liberdade, senão que por seu intermédio são dadas aos participantes do mercado, por vezes, informações importantes sobre a sua performance no mercado. Na sequência, eles podem, por exemplo, otimizar suas ofertas ou aperfeiçoar elementos individuais da prestação. Além disso, as discriminações podem também representar um enriquecimento direto do mercado. É de se pensar, por exemplo, em um agente de viagens que se concentra em clientes mais velhos, em uma academia de ginástica que só aceita mulheres ou em promoções que prevêem descontos para crianças aniversariantes. É de se registar, ao fim e ao cabo, que as discriminações fazem parte da essência de uma economia de mercado e constituem o núcleo da autonomia privada. Uma proteção contra discriminação é, por conseguinte, primeiramente justificada quando for iminente o risco de uma exclusão considerável. ${ }^{60}$ A identificação de uma exclusão considerável depende, principalmente, da combinação de três fatores: ${ }^{61}$

\section{aa) Sinal objetivo de discriminação}

Como primeiro pressuposto, um sinal de discriminação reclama que o intersubjetivo seja considerado como critério adequado para um desfavorecimento. Exemplos fundamentados historicamente constituem a "raça”, a religião ou, por exemplo, a identidade sexual. Em contrapartida, contanto que um indivíduo exclua outro em virtude de um sinal periférico, não considerado, de modo geral, relevante, trata-se de uma consequência - em princípio aceitável - da concorrência e da autonomia privada.

\footnotetext{
${ }^{57}$ Ver, com respeito aos desfavorecimentos em virtude da pobreza, ainda, DUMMETT, Implementing European Anti-Discrimination Law: A Critical Analysis. In: NIESSEN/CHOPIN, The Development of Legal Instruments to Combat Racism in a Diverse Europe (2004): 245 ss.

58 1968, p. 20 s.

${ }^{59}$ Cf. CAPLOVITZ, The poor pay more, 1963; SCHIEK, Differenzierte Gerechtigkeit, 2000, p. 246 ss., com documentação comprobatória adicional.

${ }^{60}$ Crítico com respeito à necessidade de hierarquização BROWN, The Race Directive: Towards Equality for All the Peoples of Europe? (2001-2005) 21 Yearbook of European Law 223; BAER, „Ende der Privatautonomie" oder grundrechtlich fundierte Rechtssetzung?, ZRP 2002, 290 ss. (294).

${ }^{61}$ Cf. NEUNER, Diskriminierungsschutz durch Privatrecht, JZ 2003, p. 57 ss. (62 ss.); ainda RIESENHUBER/ FRANCK, Verbot der Geschlechtsdiskriminierung im Europäischen Vertragsrecht, JZ 2004, p. 537; LARENZ/WOLF, Allgemeiner Teil des Bürgerlichen Rechts, 9. ed. 2004, § 34, números de margem 38 ss.
} 
Quem, por exemplo, oferece seus produtos apenas a homens de um especial signo do zodíaco, exclui muito mais a si próprio do que aos outros. Um sinal de discriminação se converte em um problema de exclusão social, em princípio, a partir do momento em que ele passa a ser considerado relevante como critério de desfavorecimento por um número representativo de sujeitos de direito privado. Um acordo intersubjetivo pode ser estabelecido, do ponto de vista metodológico, sobretudo por meio de dois caminhos: por um lado, mediante um olhar para a história, na medida em que determinados sinais da personalidade se revelaram especialmente suscetíveis de discriminação. Por outro lado, por meio de um olhar para as convenções internacionais antidiscriminatórias, as quais atestam - também de modo consensual - a necessidade de regulamentação relativamente a determinados motivos de discriminação. Como medidas reguladoras relevantes do ponto de vista intersubjetivo manifestam-se, assim, inúmeros dados da personalidade, como "raça”, religião ou orientação sexual. Com respeito, por exemplo, ao sinal "idade”, tenho, em contrapartida, dúvidas se ele realmente representa um critério sistemático de exclusão no tráfego jurídico.

\section{bb) Dignidade de proteção de terceiro}

Ao lado do risco objetivo de exclusão de um sinal de discriminação, há de se considerar a necessidade concreta de proteção do discriminado. Diversos critérios são, para isto, significativos. Depende, especialmente, se o sinal de discriminação é inalterável para o atingido (como, por exemplo, a "raça”, o sexo ou uma deficiência) ${ }^{62}$, se não há possibilidades de evitação em virtude da estrutura do mercado (por exemplo, por causa de um monopólio) e de o quão intensamente o discriminado está a depender da prestação (por exemplo, bens básicos da vida diária, bem como prestações de natureza informativa importantes para o desempenho do papel de cidadão).

\section{cc)Interesse do decisor em diferenciar}

Em terceiro lugar, há de se considerar, por fim, o interesse do decisor em diferenciar. Nisto, há de se distinguir sobretudo entre dados pessoais inalteráveis e alteráveis, porquanto os últimos são, em princípio, adquiridos de maneira autodeterminada e se prestam, portanto - também do ponto de vista ético -, potencialmente como máximas gerais de atuação. Diferentemente do Estado, o cidadão não está obrigado a professar nenhuma neutralidade religiosa ou ideológica. Ele pode, antes pelo contrário, desenvolver-se, em princípio, livremente em todos os âmbitos da vida, aderir a associações, e, por meio do seu poder de mercado, perseguir também objetivos externos ao mercado. Com respeito a sinais inalteráveis como "raça” ou sexo, estão, em contrapartida, em princípio excluídas decisões de preferência autodeterminadas. Não há, por isso, também nenhum motivo de natureza ética digno de reconhecimento para recorrer a tais sinais - de modo geral - como critério de discriminação. Tão somente no ambiente privado, familiar e de moradia são irrenunciáveis diferenciações correspondentes para o desenvolvimento da personalidade - como, por exemplo, na escolha do cônjuge ou parceiro, que será precisamente tomada com base no sexo, confissão religiosa ou outros dados da personalidade.

\footnotetext{
${ }^{62}$ Ver, ainda, SCHIEK, A New Framework on Equal Treatment of Persons in EC Law (2002) 8 European Law Journal 309 ss.; KERN, Rassendiskriminierung im Zivilrecht, 2007, p. 132 ss.
} 


\section{Visão de conjunto}

Em visão de conjunto, mostra-se necessária uma proteção antidiscriminatória abrangente e jurídico-prestacional relativamente aos sinais "raça”, sexo e deficiência. Correspondem a estes três critérios - no plano do direito internacional - três Convenções das Nações Unidas, que servem ao combate de todas as formas de discriminação em virtude da raça, contra mulheres, bem como à proteção de pessoas portadoras de deficiência. ${ }^{63}$ Com respeito a outros critérios reprováveis, teria sido suficiente, na minha opinião, uma cláusula geral que abrangesse discriminações especialmente massivas e garantisse um manejo judicial flexível. O legislador alemão estendeu nitidamente a proteção ${ }^{64}$ e apenas no último minuto retirou outra vez o critério da ideologia do $\S 19$ da Lei Geral de Igualdade de Tratamento. Pode-se criticar esta proteção extensiva, mas o legislador possui uma ampla margem de conformação e pode, por força do seu mandato democrático, intervir de maneira ativa nas relações jurídico-privadas. Exigências ocasionais dirigidas à magistratura, no sentido de que a Lei Geral de Igualdade de Tratamento deve ser interpretada de modo restritivo $^{65}$, hão de ser rejeitadas precisamente sob o aspecto da separação de poderes. De resto, a práxis já se ajustou preponderantemente à nova situação jurídica, modificando, por exemplo, condições de contratos de seguro que, de maneira discriminatória, atribuíam os custos relacionados à gravidez e à maternidade apenas às mulheres.

\footnotetext{
${ }^{63}$ Ver, a respeito, pormenorizadamente, SCHIEK. In: SCHIEK (Org.), Allgemeines Gleichbehandlungsgesetz, 2007, introdução aos números de margem 15 ss., com documentação comprobatória adicional.

${ }^{64} \mathrm{Cf}$., acima, nota de rodapé 6.

${ }^{65}$ Cf., por exemplo, MEDICUS, Allgemeiner Teil des BGB, 9. ed. 2006, número de margem 479a, com documentação comprobatória adicional.
} 